\title{
Editorial
}

\section{Cambios en el escenario mundial y nacional}

Cuando en 1989 se firma el cierre de la guerra frla y en enero de 1991 se inicia una guerra electromecánica, que en mes y medio descarga un potencial destructivo similar al de la segunda guerra mundial, algo muy serio ha cambiado en el escenario internacional. Cuando en esas mismas semanas se lleva a cabo un intenso diálogo entre las representaciones gubernamental e insurgente con el objetivo de poner fin a una guerra y readecuar la letra de la Constitución a los propósitos de la paz en democracia, algo muy serio se quiere reestructurar en nuestro escenario nacional. A primera vista se tratarla de dos escenarios diferentes: el uno desarrollando escenas de guerra y el otro cerrando el telón con la firma de la paz: En realidad se trata del mismo drama o tragedia del mal llamado "orden mundial", del cual es un reflejo nuestro orden nacional.

Los últimos meses de 1989 y los primeros de 1990 nos trajeron ciertos aires de optimismo. Las superpotencias parecian reconciliarse y poner fin a la carrera armamentista atómica. Ni vencedor ni vencidos, sino más bien convencidos del horror de la amenaza atómica. Hace un ano, febrero de 1990, se reunian en París figuras representativas de los palses del Este y Oeste europeo, y abrían el Foro de la Sorbona con la siguiente frase: "Los historiadores nos han ensehado que el siglo-XX $c^{-}$ menzó en 1914. Sin duda, a partir de ahora, debemos decir que 1989 marcó el comienzo del siglo-XX|". En este Foro de la Sorbona (1990), al igual que en el Foro de Moscu (1989) y de Barcelona (1988) se dis- 
cutia, junto con los problemas políticos-económicos-democráticos del bloque-Este, el proceso de su integración en el Occidente europeo y en el marco económico internacional. Adios al Pacto de Varsovia, adios a la Alianza Atlántica, y bienvenida la Nueva Europa Unida. Se iniciaba un segundo milenarismo de paz y de recuperación económica, simbolizado en la demolición del Muro de Berlín.

Ha pasado un ano sin que floree la paz ni la recuperación económica del lado de allá o de acá del océano Atlántico. Más bien son otros muros, otros brotes de insolidaridad esperados e inesperados los que vienen a resquebrajar el nuevo orden internacional. La Unión Soviética se convierte en des-unión soviética con surgimiento de las nacionalidades reprimidas 0 aceptadas. La Yugoeslavia de Tito amaga derivar a guerra civil étnica. Los alemanes del Este se consideran ciudadanos de segunda y extranjeros en su propio pais; "no nos quieren en la Nueva Alemania". Las recién adoptadas sociedades del Este sufren del sindrome de insolidaridad cuando el Oeste les comienza a mirar con recelo y sienten "los comportamientos xenófobos y de miedo respecto del pobre europeo oriental que llama a la puerta del occidente opulento". La nueva Europa no es un gran mercado unido, sino un mosaico de nacionalidades a la defensiva. La Europa unida está dividida por la lógica del mercado competitivo.

La China misteriosa sigue siendo otra incógnita y no quiere repetir la historia de la URSS. Gorbachov se equivocó al poner por delante la reforma política y la glasnot, que entorpecen los intentos de la reforma económica y han abierto el camino al estallido de las nacionalidades. Jiang-Zemin y Li-Peng, Secretario del Partido y Primer Ministro, han optado con realismo chino por "conjugar una no-reforma en lo político con una si-reforma en lo económico", porque es indispensable un mayor contagio de las economlas capitalistas para modernizar ese inmenso país. Pero los movimientos democráticos, simbolizados en la plaza de Tiannanmen, y las reformas liberales iniciadas desde 1979 por el venerable Deng Shiago Ping ¿Podrán soterrarse por largo tiempo? Porque también estalló la olla en Albania y puede saltar en Cuba.

En el nuevo desquiciamiento mundial ha sido el conflicto del Golfo Pérsico quien ha venido a develar tensiones coloniales latentes desde antiguo, antagonismos culturales, determinaciones imperialistas, traducido todo ello en desafortunadas invasiones, guerra y destrucción masiva. Bajo el título de "El nuevo orden internacional: la pax-americana" se dedica un momento de reflexión a la lógica de la guerra, una ética sin moral; reflexiones que no están fuera de contexto en un pals que conoce a la vez la guerra y la pax-americana. La guerra frla, la 
amenaza atómica era temible, pero era menos poslble porque no habrla vencedores ni vencidos sino sólo desaparecidos. Lo terrible es y slgue siendo la guerra caliente, la que fue precedlda por un proceso coloniasta y por un jugoso comercio de armas. Vencedores y vencidos lucharon con las armas vendidas por los primeros. Armas por petróleo y armas por sangre. Con la guerra se destruyen dos valores: la vida de clentos de miles de personas. "La guerra es un horror para todos" dirá J. K. Galbraith. También se ha convertido en epltaflo tiplco que "la primera victima de la guerra es la verdad". Todo esto ha sucodido en el Golfo Pérsico: se ocultó la verdad. Pero aparecieron muchas verdades veladas. Un nuevo muro de insolidaridad entre el ampllo Occldente y el Medio Oriente. Se desmoronó el muro de Berlín, pero en el confllcto del Golfo Pérsidco se levanta no sólo el muro del medio Orlente, sino que se refuerza la muralla Norte-Sur.

El derroche de potencial destructivo ha sido una muestra sensible de 10 que puede hacer el big-brother ampliado contra cualquier pals del tercer-mundo que ponga en peligro los intereses económicos o polittcos del Norte opulento. No se justifica, porque es condenable, la Invasion de Kuwait por un dictador mesiánico e imperialista; pero por la misma razón no se justifica llegar al recurso último de la guerra que, por destruir al dictador, mata a cientos de miles de inocentes. El fin no justifica los medios; todavia peor, si el fin de la destrucción es lograr la recuperación económica de los países que primero destruyen y luego se adjudican el botín de la reconstrucción. El aún impredecible conflicto del Medio Oriente ha venido a desquiciar el posible orden y equilibrio mundial.

La Europa Unida ha mostrado su debilidad política, frente a la superpotencia militar, para mediar y evitar las consecuencias destructoras de la guerra. Tan grave como la debilidad política es que en el nuevo orden internacional vuelva a tener los derechos de primogenitura el poder militar sobre el poder económico y civil. Se militariza el orden internacional y la pax-americana reedita el adagio romano "si vis pacem para bellum" (si quieres la paz prepara la guerra). Si la Asamblea General de las Naciones Unidas hizo serios esfuerzos por interponer soluciones político-económicas, su Consejo de Seguridad y sus cinco grandes exportadores de armas cedieron hasta la aprobación de la guerra final. Con ello se replantea el papel y la reestructuración de las Naciones Unidas.

Política y económicamente se inicia una readecuación de naclones y continentes, atractivos los unos, olvidados los otros. La afirmación de que el Este va hacia el Oeste y el Oeste camina hacia el Este sloue 
marcando la línea del mercado y de la inversión al interior de Europa, pese a los recelos nacionalistas. Las giras de hombres políticos y empresarios norteamericanos y japoneses por varios países del Este europeo dan a entender que la Nueva Europa puede ser el recinto privilegiado de la gran inversión. Por su parte, las antiguas economlas socialistas aceptan que su recuperación necesita de la tecnologla y de los préstamos del bloque capitalista. Las ayudas alimentarias y otros bienes básicos aprobados por USA y la Comunidad Económica Europea a favor de la URSS manifiestan el interés que ese occidente tiene por integrar al bloque-Este en el recinto de la economía de mercado. Además, ese nuevo Plan Marshall, a veces votado y a veces vetado, sive de catalizador y según los casos del acusador del respeto de los derechos humanos en aquellos paises. Aunque la reestructuración sea más lenta y costosa que lo previsto a primera hora, la Nueva Europa está llamada a ser el lugar privilegiado del gran mercado y de la gran inversión. Europa el "hogar común" de la inversión.

Otro bloque de atracción económica, tanto por sus riquezas como por su conflictividad, será el Medio Oriente. Aqul se mezclan la geopolítica, la geoeconomía y la geoestrategia militar. La Meca, en sentido ampliado, se ha convertido en un lugar más conflictivo para las peregrinaciones, pero más atractivo para las inversiones. Después de todo el Medio Oriente sigue siendo el corazón de la industria occidental, bombeándole el oro-verde. Además es un lugar conflictivo y en buena parte destruido. Ofrece la gran oportunidad de un amplio mercado productivo y de un abundante comercio de armas, a menos que se haya aprendido la lección de que las armas se pueden volver contra el que las vendió. De momento los grandes beneficiarios de la reconstrucción son los EE.UU. y su acompanante el Reino Unido. Esto permite a la vez una presencia norteamericana en aquel lado del Atlántico, una especie de mini-OTAN. A la Europa en conjunto se le está vedando ese coto de caza del Medio Oriente. Alemanes y japoneses no han sido invitados a la reconstrucción y los soviéticos, observadores a distancia, condescienden con la creciente intromisión norteamericana para no entorpecer el flujo de créditos que tanto necesitan y no enfriar más el proceso avanzado de la desarmamentización atómica. El gran poder militar trata de reponer su iniciada contracción económica.

En el quinto centenario del descubrimiento de América corremos el peligro de quedar al descubierto. Vistos desde Europa somos "libres pero pobres". Libres porque se ha dado una transferencia de gobiemos militares a gobiernos civiles. Pero pobres en razón de las políticas económicas antes adoptadas, de la adversa coyuntura internacional, de los derroches de la administración pública, y pobres porque siempre han 
sido muchos más los pobres que los ricos. Si las convulstones soclales han bajado de tono, el monto de la deuda externa sigue sobrepasando los $\$ \mathbf{4 1 0 . 0 0 0}$ millones. Frente a otras alternativas más rentables para el crédito y la inversión América Latina puede quedar el descublerto. Algunos paises comienzan a cambiar la deuda externa por "deuda verde" (Play Brady), o deuda por naturaleza que atrae a ciertas sociedades ecológicas. Mientras tanto el conjunto de naciones debe acoplarse al nuevo reglamento de la estabilización y ajuste estructural para ser sujetos de crédito, aunque a los pobres les cueste pagar los gastos de acomodación, porque siempre "cuesta caro el ser pobre".

A este propósito se emiten tesis diferentes. Algunos los exponen en cuatro palabras: "el Este contra el Sur", dando a entender que el crédito y la inversión circularán en línea horizontal y no vertical. Otros nos inyectan algun optimismo subrayando que hay un propósito de "Hacer las Américas: EE.UU. y la Comunidad Económica Europea vuelven tímidamente sus ojos hacia Latinoamérica tras la guerra del Golfo". Movidas quizás por razones geoestratégicas o geoancestrales varias delegaciones europeas han repasado el continente latinoamericano ofreciendo su colaboración a proyectos regionales. De nuestra parte, la deuda externa y la crisis intema están forzando las uniones regionales en el cono-SUR, en la América Meridional, algo en Centroamérica, mientras que México lucha por ser integrada en el gran mercado anglofrancés de USA y Canadá, aunque algunos sindicatos-USA le miran como mal adversario de mano de obra barata. América Latina deberá entrar en un mercado mundial, bastante proteccionista, a través de sus mercados regionales, a sabiendas de que la suerte de estos últimos dependen de la recuperación del primero. Ahora es Latinoamérica la que tiene que descubrir el viejo mundo.

Dentro de este escenario mundial, que ha vuelto a potenciar la guerra y los valores militares por encima de otros valores éticos y humanos, se abre nuestro más pequeho y más conflictivo escenario salvadoreno. Un título para nuestro drama pudiera ser: "un paso adelante y dos pasos atrás". Un paso adelante, porque los mayores esfuerzos del partido-Gobierno pretenden convencernos de que ya nos vamos estabilizando y reajustando y somos sujetos de crédito y confianza intemacional. Tenemos una buena imagen económica. Pero el resto de la Imagen la tenemos en cuarto mengũante. Dijimos antes que "la primera victima de la guerra es la verdad". Es verdad que algunas variables macroeconómicas han mejorado: el PIB, el I.V.A.E., las exportaclones, las reservas netas internacionales... Pero no es verdad sino un grave error de composición sui-generis que, junto con los datos macroeco. nómicos, se esté dando una mejora equitativa de todos y cada uno de 
los grupos sociales componentes del conjunto nacional. El frente de la pobreza, dejando de lado dependencias partidistas, sigue englobando a porciones crecientes de la población, golpeados conjuntamente por el largo proceso de desempleo-inflación.

Cuando los principios filosóficos expuestos en el frontisficio de nuestro modelo económico de mercado enuncian los ideales de libertad, igualdad, justicia, propiedad, competencia... están diciendo una verdad: que se trata de ideales, pero no de valores reales en nuestro país. Para que haya libertad tiene que haber liberación; para que haya igualdad hay que reducir las discriminaciones socioeconómicas; para que haya justicia hay que suprimir la impunidad y los abusos de todo poder; para que haya propiedad hay que crearla, compartirla y desconcentrarla; para que haya competencia hay que controlar el efecto-dominación de los grandes sobre los pequehios.

Nuestro pequefio escenario repite los rasgos del gran escenario del orden mundial. La guerra nos ha hecho hombres de guerra con todas sus consecuencias; necsitamos siempre un adversario y si no existe bo inventamos, porque el que no está conmigo está contra mí. Se ha hecho una simbiosis de la guerra y del diálogo. Se utiliza el diálogo para terminar la guerra y se utiliza la guerra para terminar con el diálogo. Voces conciliadoras patrocinan la "concertación nacional" (ECA: 1990; p. 747...) y la "reconciliación nacional" (Pronunciamiento-UCA: 2 mayo 1991) en un momento en que es necesario concertar y reconciliar el fin de la guerra con el espíritu de la Constitución. "La letra mata, y el espíritu vivifica", pero hay gente que está a favor de la letra y también de la pena de muerte.

La verdad civica trata de abrirse paso y a ciertos poderes les llama impunidad a otros corrupción, y a otros prebendas y componendas. Los derechos humanos se miden en el termómetro de los informes de las Naciones Unidas, y las asociaciones gubemamentales y no gubernamentales se adelantan a colorear los avances y los retrocesos. Por lo menos ya es un derecho humano el que se pueda hablar de los derechos humanos. $Y$ hablando de los derechos humanos, surge un serio problema si llegamos hasta el cese del fuego: ¿cómo vamos a convertir en sociedad civilista una sociedad militarista? La respuesta literal es fácil y las palabras ya las podemos pronunciar: desmilitarización, depuración... Pero, como dicen los economistas, el problema está en ¿quién, cómo y para quién?- Porque además hay que desmilitarizar muchas conciencias: ¿cómo desmilitarizamos el espíritu de venganza, de violencia, del ojo por ojo y dentadura por diente? Nos queda un largo camino por andar en este proceso de estabilización y ajuste estructural civico-político-militar. 
En el campo económico los informes oficiales rezuman optimismo Conviene sehalar un rasgo positivo: hay informes, hay un esfuerzo serio de presentación técnica, hay pronósticos de realizaciones temporales..., y por supuesto hay quienes los critican, lo cual es un avance. Pero tal vez faltan los diagnósticos veraces de sus consecuencias presentes y futuras. No basta decir que si los resultados son adversos el partido perderá las próximas elecciones, porque en el interim de cuatro o cinco anos habrá otras mayorlas que perderán mucho más... Oticialmente se admite que las políticas del ajuste estructural generan efectos iniciales adversos a las mayorlas populares, a compensar con la función subsidiaria del Estado. Lo contradictorio de nuestra situación es que la pobreza no es algo inicial de 1989, ni de 1980, y los más pobres de los pobres ponen en duda el que se les tome en serio. Los problemas de la educación, salud-nutrición, vivienda, familia, empleoseguridad-social, amén del deterioro ecológico se transfieren al segundo rango del Desarrollo Social, a subsidiar por un Estado, que debe gastar menos y que por ley no debe pedir créditos al BCR. Mientras el Estado deba dedicar casi un tercio de su presupuesto a la defensa militar poco le quedará incluso para defender a la población de la peste del cólera que ronda nuestro pais.

Con un claro-obscuro combinado de argumentos y semiverdades se han minusvaluado las funciones estatales. Más que de reestructruación y tecnificación de la Administración Pública se ha procedido a una mutilación de sus deberes y funciones, a excepción de la gravosa administración de la guerra. El nuevo eje es la privatización, silenciando su traducción histórica en concentración. Tampoco se cuestiona si el típico sector privado está en capacidad de ejercer este papel central. No se habla de incapacidad del sector, sino de la necesidad de la reconversłón industrial, de la reconversión bancaria, de la reconversión agricola. Contraviniendo, de hecho, las normas del modelo es el Estado -apoyado en la realidad- quien fuerza las reconversiones y subsidia la privatización. De la misma manera que en el escenario mundial hay un Norte y un Sur, también en todo este proceso de privatización hay un Norte-formal sobre un Sur-informal más pobre y numeroso. Las medidas del nuevo modelo van creando tensiones sociales dentro del modelo; los micros o pequehos reclaman su taburete en la mesa del reparto del crédito y de la asistencia técnico-financiera, para sostener al menos una mínima supervivencia.

Por su lado la inflación y el desempleo aumenta el número y cuaIldad de la pobreza, mientras que la inseguridad generalizada amaga ol derecho a la propia vida. Olvidando que la guerra nació de la pobreza, la pax-americana subsidió más la guerra que la pobreza, y apoya una 
economia de libre mercado alli donde dos tercios de la población no puede llegar al mercado. Se ha tratado de acabar con el adversario con la guerra. Como la historia es la maestra de la vida, parece que ahora nos inclinamos por el cese de la guerra. Nos queda por delante entrarle en serio a la guerra contra la pobreza y la inseguridad. Nos queda mucho camino por alcanzar la democracia. Un paso adelante y dos pasos atrás. Nuestro pequeho escenario es una parcela significativa del gran escenario donde se quiere engendrar, con lágrimas, el nuevo orden internacional. 